\title{
SABERES Y ENTORNOS: NOTAS PARA UNA EPISTEMOLOGÍA DEL TERRITORIO ${ }^{1}$
}

Knowledge and Surroundings: Notes for an epistemology of territory

Nelson Vergara*

Resumen

El territorio es una realidad que se manifiesta con una pluralidad de ámbitos o lados que aquí llamamos perspectivas. Dos de ellas nos parece que, teóricamente, siempre se correlacionan: la perspectiva metafísica y la perspectiva epistemológica. Según la primera el territorio es un tipo de realidad efectiva, aunque no siempre de índole concreta, mientras que en la segunda, es una realidad nocional, un concepto, una teoría. En este trabajo nos aproximamos a develar el territorio en esta segunda condición, reseñando lo que en general entendemos por realidad epistémica y lo que nos parece ser el territorio en cuanto realidad epistémica e indicamos las correlaciones que se nos presentan entre ambas perspectivas.

Palabras clave: Espacio, territorio, espacialidad, territorialidad.

Abstract

Territory is a reality which manifests itself through a plurality of areas and factions that we will call here perspectives. Two of them seem to us, theoretically, are always correlative: the metaphysical perspective and the epistemological perspective. According to the first, territory is a kind of effective reality, though not always in a concrete fashion, while the second is a notional reality, a concept, a theory. In this essay we approach territory through this second condition, reviewing what we generally understand as epistemic reality; and what territory seems to be to us in regard to an epistemic reality, and we indicate the correlations that appear between both perspectives.

Key words: Space, territory, spaciality, territoriality.

\section{APROXIMACIONES A LAS REALIDADES "EPISTÉMICAS".}

La convicción de que no solamente vivimos cambios profundos a nivel de realidades de hecho (políticas, económicas, tecnológicas, morales, estéticas, etc.) sino que, también, esos cambios se evidencian en los modos de conocimiento, de comprensión e interpretación de ellas es una cuestión de lo más relevante en nuestra época; siendo muy significativo que tal cuestión se manifiesta como un fuerte cuestionamiento a las maneras tradicionales, modernas, de aprehensión de lo real, lo que se ha venido asumiendo con el llamativo título de cambio de paradigmas.

\footnotetext{
${ }^{1}$ Esta publicación es producto de la ejecución del proyecto Fondecyt № 1080665 "Las sociedades litorales como sistemas de prácticas y saberes tradicionales y científicos: la caleta como modelo de imaginarios pesqueros y dinámicas de uso y apropiación de recursos marinos".
} 
Un supuesto fundamental en este contexto es que ningún hecho puede ser entendido si no se lo sitúa en los marcos socioculturales en que acontece; de modo que los cambios paradigmáticos constituyen también realidades inseparables de esos marcos, a los que recursivamente contribuyen a formar. Partiremos, entonces, de este reconocimiento y de algunas preguntas iniciales como las siguientes ¿En qué consiste, epistemológicamente, el cambio paradigmático que estamos señalando?, ¿Qué efectos o alcances tienen estas transformaciones en la constitución de nuestros mundos, más acá de la Modernidad?, preguntas que intentamos responder en conjunto en esta primera parte.

$\mathrm{Al}$ establecer las preguntas en dirección epistemológica, queremos reiterar que un paradigma trasciende esta dimensión cognoscitiva, esto es, que no se agota en ella, lo que hace que los cambios paradigmáticos sean siempre cuestiones bastante complejas; condición cuyo reconocimiento es, históricamente, reciente. Lo anterior se ve reflejado en el hecho de que, siendo lo epistemológico un asunto que en lo esencial trata de dilucidar las formalidades de los conceptos o teorías, esta dilucidación es imposible de realizar al margen de las circunstancias en las que se piensan los conceptos, de manera que, al concebirlos, nos vemos compelidos a pensar, también, las situaciones en que se dan y los distintos contextos que interactúan con ellos, por lo que debe ser posible leer en los conceptos, tanto las significaciones pertinentes a la realidad de sus referencias, como las condiciones en que dichos contextos se dan teórica y prácticamente, cómo se constituyen y cómo se desenvuelven, momentos que en la historia de los paradigmas se reconocen como períodos de normalidad o como períodos de crisis. Formalmente, desde Kuhn (1993) —aunque en rigor es más antigua, ya que el concepto se usaba ya en el siglo XIX - esta cuestión marca una transformación radical en la forma de concebir la historia de las ciencias, la que ya no puede ser entendida como en la modernidad, en términos acumulativos y lineales.

La consecuencia inmediata de lo anterior es la convicción de que vivimos una situación marcadamente crítica. Resultado de esto es la creencia en la inestabilidad de los paradigmas, lo que se ilustra en la velocidad con que se van erosionando sus perfiles y promoviendo ya no tal o cual reforma en su configuración y práctica, sino que su sustitución, su reemplazo. Y no se trata, solamente, de cambios radicales en el interior de las disciplinas, sino de sus relaciones con otras disciplinas (dando lugar a relaciones inter, multi o transdisciplinarias) y con el mundo en torno (local, regional, global, etc.) que se acentúa, hoy día, por las condiciones de globalización socio-histórica que instituye contextos y situaciones como entornos insoslayables. De este modo, en la cuestión paradigmática, no sólo nos enfrentamos a nuevas ideas acerca de la realidad de los objetos que interesan a la ciencia y, en general, a todo saber --incluidos los objetos del sentido común — sino que, también, a las 
nuevas ideas acerca de lo que es el saber o el conocimiento. Por esto, se ha afirmado con tanta convicción que estamos frente a realidades epistémicas que debemos asumir desde condiciones de alta complejidad las que, por lo pronto, rechazan toda idea favorable a la tradicional teoría moderna de los datos elementales como únicas bases seguras y ciertas, doctrina moderna que promueve y defiende a ultranza el positivismo y neopositivismo.

Entre las condiciones más reveladoras de la complejidad epistemológica, interesa particularmente destacar tres cuestiones claves que, entre otros, Edgar Morin ha venido desarrollando en sus investigaciones (1982; 2006): a) la creciente decepción por la búsqueda de la simplicidad tal como la entendió la época Moderna; b) el abandono progresivo del ideal de autonomía disciplinaria en el sentido moderno del término; c) la búsqueda de un paradigma que se sostenga sobre principios que apuesten por la complejidad.

En cierto modo, las dos primeras cuestiones constituyen aspectos de un mismo paradigma, que desde Descartes dominara toda la Época Moderna y que E. Morin (2006) denomina paradigma de la simplicidad. Cada aspecto, sin embargo, es significativo por sí, como es significativa su conjunción. Con más o menos variaciones este modelo de investigación ha llegado hasta el positivismo del siglo XIX y ha dominado, desde allí, una buena parte de la ciencia del siglo $\mathrm{XX}$, incluido el neopositivismo $\mathrm{y}$, en cierto sentido también, la variante radical del constructivismo contemporáneo, a lo menos en la línea de Heinz von Foerster y Ernest von Glasersfeld.

Al respecto, según E. Morin (2006), dos son los asuntos que refieren, en términos de principios, a lo que denominamos la búsqueda de los datos elementales, siempre tan caros a la Modernidad: el principio de la distinción analítica y el principio de la reducción a lo elemental. Y en este plano, también estos aspectos principiales del paradigma de la simplicidad se reenvían y condicionan mutuamente: el análisis es, desde ya, reductor y la reducción sólo puede conducir a los datos requeridos por el análisis. Por esto, el programa de la Modernidad, sobre todo a nivel positivista, raya en lo dogmático al proponer a ultranza la condición absoluta y la proyección de sus verdades como incuestionables, con tal de que se sigan sus preceptos, esto es, de que se cumpla con sus requerimientos; $\mathrm{y}$, entre ellos, junto con la herencia cartesiana del análisis y la reducción, la exigencia empirista de someter las ideas al escrutinio de la experiencia, en el sentido que para el positivismo tiene que someter algo a tal concurso. Ortega (1962, 1966), Popper (1992), Sartre (1967), Morin (1982, 2006), Castoriadis $(2002,2007)$, entre tantos, se han referido muy críticamente a estas exigencias, de las que dependió el encuentro y mantención de las certezas modernas, tanto científicas como políticas, haciendo de la simplicidad una fe y una doctrina. El Discurso del Método es, y ha sido siempre, el modelo que mejor ilustra el estado de espíritu propio de la Época Moderna, su sensibilidad y su 
racionalidad. La propia burguesía, escribió Sartre (1967), puede ser definida por el uso que hace de ese espíritu dominado por la reducción analítica y que, notoriamente, trasciende el ámbito científico.

Pero, no es solamente lo real efectivo lo que sufre el embate de la reducción analítica. También actúa sobre otras formas de lo real, como es lo real conceptual, esto es, el conocimiento mismo. De hecho, en este terreno, la Modernidad instala la dicotomía de sujeto y objeto y pretende darle validez en todo y para todos: el mundo, la extensión, queda de un lado; el pensamiento, la cogitatio, queda de otro, separados y distintos. Y así como lo extenso para ser comprendido tiene que ser separado en tantas partes como resulten necesarias, el pensar - al someter a análisis lo que le es propio - tiene que hacer lo mismo. Entonces, se instalan las disciplinas como una consecuencia del rigor del análisis y se consolidan, también, bajo la categoría de autonomía relativa. En la Modernidad, la ciencia y la cultura, en general, son disciplinarias y tienen su propia esfera de acción. Por esto, Descartes — desde el inicio - recomienda no con-fundirlas y, por esto, cada una de ellas entra en procesos de dominancia que significa reclamar para sí un determinado dominio de lo real, incluido el arte que — según Heidegger (1960) — cae, entonces, bajo el dominio de la Estética.

Pero aun cuando las crisis se sostengan en determinadas decepciones como son las que terminan por poner en discusión e incertidumbre el valor de estos principios que, en otros ámbitos más recientes, se han conocido como la decepción por los grandes relatos, ninguna crisis ha podido sobrevivir y superarse sin un proyecto, sin un afán, a veces muy soterrado, de emociones y de sensibilidades que quieren construir lo nuevo desde nuevas bases. Así, a la crisis de los principios modernos y sus fundamentos en la Razón, el Progreso, en la linealidad de la Historia Universal, como los nombra G. Vattimo, le sigue una fase de propuestas que pretenden instalar nuevos paradigmas. En el contexto que estamos considerando, E. Morin llama a esto el Paradigma de la Complejidad (2006) cuyos principios más programáticos en su concepción son la dialogicidad, la recursividad, la hologramaticidad, principios que se resumen en la idea central que afirma que lo real es siempre un tejido, una trama, un entramado de diversidades y diferencias, tanto como de identidades, un complejo de relaciones, interacciones e inter-retroacciones entre hombres y ambientes (o entornos); entre efectividades, virtualidades, conceptos, imaginaciones, etc., es decir, un todo de partes que se interpenetran y codeterminan. Y esto es válido tanto en lo que se ha denominado lo ontológico como lo epistemológico y lo valórico, sea hacia fuera o hacia dentro de sí mismos. Por esto, sabemos ahora que Afuera y Adentro no son ya absolutos sino relativos uno al otro y que se requieren mutuamente, también. De este modo, categorías concebidas como dicotomías, por ejemplo, Subjetividad y Objetividad; Hombre y Mundo; Conciencia y Objeto; Razón y Experiencia; Apariencia y Realidad, etc. — dicotomías que con tanta convicción revelaron a la 
Modernidad - manifestaron siempre, desde el espíritu de la complejidad, su condición de asuntos definidos por coexistencia. Así dice Sartre, en un texto muy significativo (1965) no es en la intimidad donde vamos a encontrarnos, sino en el afuera, en lo otro que nosotros mismos, pero donde lo otro, de alguna manera, forma parte esencial de lo que somos.

Según esto, la transformación más significativa en las realidades epistémicas se manifiesta, entonces, en el paso de la autonomía de lo elemental a la coexistencia de sus partes; de la determinación y dominancia de una parte sobre otra, a su interacción e interdependencia; de su influencia unilateral y lineal que revelaría su constitución simple, a sus influencias mutuas a través de inter-retroacciones y coexponentes de sus radicales complejidades. A partir de aquí, ya no nos es posible separar, aislar, al hombre de sus entornos, así como tampoco al saber de los suyos. Como lo está probando la historia actual de las ciencias, las consecuencias de este cambio epistemológico, junto con otros cambios, es de proporciones gigantescas.

\section{EL TERRITORIO COMO REALIDAD EPISTÉMICA}

Como hemos afirmado - en una tesis ampliamente difundida y que comparten muchos autores - se sostiene, con leves variantes, que vivimos una suerte de revolución epistemológica. Así, se dice que observamos el pasaje "de un gran momento de un imaginario logo centrado, centrado en la palabra a un imaginario que va a estar loco/locus centrado, centrado sobre el espacio" (Maffesoli, 2004). Años antes, en un texto que se ha vuelto emblemático, afirmaba Foucault (1999) que así como el siglo XIX había sido el gran siglo de la historia, "tal vez la época actual sea más bien la del espacio" señalando, así, el gran giro que se estaría produciendo en estas coordenadas fundamentales de la existencia humana socio-histórica. Este encuadre general epistemológico —que en nuestro país y en Latinoamérica ha encontrado ecos también - apuntaría no solamente a una característica de la época, sino que al hecho ya señalado que nada podría ser realmente pensado y comprendido si no se lo sitúa con relación a ese marco. Todo, en general, se estaría espacializando y, con mayor razón, esa evidencia se mostraría en aquello que tiene relación directa con el espacio. Tal es el caso específico del territorio. Esta tesis que en Foucault muestra una leve indecisión cuando dice "tal vez", encuentra en Maffesoli una actitud más taxativa y amplia al proyectar sobre otros asuntos la revolución epistemológica en marcha. Y uno de ellos es el significativo asunto del retorno. Según esto, "la temática del territorio vuelve a estar a la orden del día" (Maffesoli, 2004, loc. cit.), así como en otros vuelven a estar a la orden del día el retorno de lo imaginario, el retorno del mito, la vuelta de los dioses, etc. Y esta afirmación de Maffesoli puede ser importante, a lo menos, en cuanto destaca dos cuestiones esenciales: el supuesto de que, alguna vez, el espacio y el territorio ya estuvieron a la orden del día y que por alguna razón dejó de estarlo, y el supuesto de que este retorno responde a una 
tendencia que lo trasciende y que, por lo mismo, entiende el territorio en un marco de transformaciones paradigmáticas de otros fundamentos, lo que exige repensarlo desde la radicalidad teórica que impone el nuevo imaginario y que se ha llamado revolución paradigmática (Pires), paradigma de base (R. Echeverría), paradigma de la complejidad (E. Morin), nueva episteme (M. Foucault), etc.

Sin considerar estas aproximaciones como recomendables en su estricta particularidad, preguntamos entonces: ¿Cómo se nos presenta el territorio hoy día en tanto realidad epistémica, teniendo en cuenta su situación en el contexto de la crisis de la modernidad? ¿Qué concepto o teoría del territorio es inferible desde esas aproximaciones? O, dicho de otro modo ¿Qué aspectos del territorio, en tanto concepto o teoría, son destacables en la situación de actualidad? Hay, al respecto, una serie de notas que nos parece que son significativas.

Una primera nota es la que relaciona o entiende el territorio con o desde la noción o concepto de espacio. Lo que no es claro es la forma que asume esta relación en las discusiones contemporáneas. Veámoslo con detalle. Efectivamente, el territorio refiere una realidad de consistencia espacial. No se apunta, sin embargo, a una noción o a un concepto general de espacio, ni a una forma abstracta como el espacio geométrico; o concreta, física, como el espacio geográfico. Tampoco parece ser, primariamente, un espacio ficticio como el espacio metafórico. Es, más bien, el espacio en tanto forma parte estructural de un proyecto vital, o trayecto, en el que se articulan vidas personales y vidas colectivas con sus entornos, circunstancias o situaciones en las que el espacio-territorio funciona como el ahí donde se prevé o se espera la concreción de esos proyectos-trayectos, ya sea en un plano material, ya sea en un plano simbólico. Desde este punto de vista el territorio es, en primer lugar, la apropiación de un espacio en vista de transformarlo o transfigurarlo en algo propio, ya sea en el sentido de la adquisición como en el sentido de la identidad. De este modo, se ha dicho, el territorio es fundamentalmente un espacio de reconocimiento de sí, o de otro; el entorno donde podemos identificar lo nuestro, o lo ajeno, y tal parece ser el sentido que se quiere destacar cuando se dice el territorio como un espacio apropiado. En este contexto, nos parece que toda otra determinación espacial como es el paisaje, el lugar o no lugar, el sitio, la ocupación, etc., suponen el de territorio, como éste supone el de la espacialidad. Pero hay algo más: las nociones fundamentales de espacialidad y de territorialidad señalan, también, esa dirección, sólo que más radicalmente —diríamos, metafísicamente- y que el plano epistemológico no puede obviar, ya que los conceptos no se agotan en su condición semiótica, sino que refieren también una semántica, en el sentido que Paul Ricoeur da a esta expresión (2002). Epistemológicamente, entonces, esta primera nota del concepto de territorio, la propiedad identificatoria, nos ubica en su condición más intrínseca. 
Una segunda nota clave es que tal condición identificatoria reclama ser considerada en términos de co-relación, co-respondencia o coexistencia, lo que discute el tradicional concepto de la disyunción impuesta por el pensamiento moderno, disyunción que sólo distingue y separa los términos y sus referentes, dibujando así, como se refirió en el primer parágrafo de este trabajo, un mapa de oposiciones, antagonismos y contradicciones que ponen en tensión los objetos entre sí y a éstos con sus sujetos. De este modo, el territorio queda, de un lado, lógica u ontológicamente, mientras el sujeto queda, de otro lado, sin posibilidades de encuentro ni compenetración sino de encuentro mecánico y de un modo que los presenta como separados y condenados a no ser más que aquello que el concepto enuncia o señala, sea del orden de la extensión o del pensamiento. Desde Descartes, el idealismo se nutrió de esta diferencia, la que instituida como incuestionable y definitiva es, por lo mismo, concebida como absoluta. Así, el espacio-territorio fue pensado y vivido siempre como lo otro absoluto del sujeto.

Sin embargo, esta concepción epistemológica fue cediendo terreno ante la evidencia creciente de que lo otro es siempre otro desde alguien o para alguien; que el objeto lo es para un sujeto y viceversa, así como el mundo lo es para una conciencia y ésta para aquél, las circunstancias para un proyecto, etc. Del mismo modo, el territorio es tal para quien, individual o colectivamente pueda admitirlo como lo propio, cercano o lejano, vivido o concebido, asignado o conquistado, reconocido o desconocido, respetado o despojado, etc. De esta manera, el territorio es siempre algo de sí y algo para sí, más allá de toda determinación posterior en el orden económico o político. Podemos llamar a esta nota la condición correlativa o correlacional del territorio.

Pero la complejidad que está inscrita en este concepto nos remite a otras notas. Una tercera, que nos parece muy conectada a la anterior, tiene que ver con la necesidad de la crítica a la idea matriz de la reducción a lo elemental propia de la modernidad y de su epistemología. Según esta característica - reconocida por Sartre (1967), según indicamos antes y señalada por E. Morin (2006) como propia del paradigma de la simplicidad - la Época Moderna, afanada en la búsqueda de las reglas que según ella regían el orden de las cosas y hallándolo siempre en las leyes que determinan sus comportamientos y que los explican, procede mediante la reducción de unas cosas a otras destacándose, en esto, la puesta al descubierto que la realidad última de lo que hay es siempre simple y elemental, representando esta simplicidad ese orden que se oculta tras las apariencias del desorden o el caos y que nos hacen pensar en complejidades inexistentes en tanto realidades y que el análisis se encargaría de conjurar, a condición, claro, de ejecutar el movimiento que el método señala y recomienda. Así, encontrado ese orden queda, entonces, establecido que la complejidad es aparente y, en lenguaje de E. Morin, recordando a Adorno (2006), la no verdad. Positivismo y neopositivismo representan a cabalidad este paradigma de lo 
simple, así como también, de un modo evidente lo hace hoy el constructivismo contemporáneo, principalmente el llamado constructivismo radical. Como todas las cosas (concepto éste muy caro al idealismo moderno), espacio y territorio parecen adecuarse perfectamente a esta noción, por cuanto "cosa" es, en esa ideología, la máxima reducción que cabe hacer en este plano, sea material o simbólica, concreta o abstracta. Y como la reducción exige la mayor prolijidad en sus afanes reduccionistas, lo más elemental será siempre aquello que ya no puede reducirse a otro, lo fundamental; el fundamento o principio. $\mathrm{Y}$ así es como el territorio se va a reducir a la noción o concepto de espacio, pero no espacio cualquiera, sino aquél tan genérico que en sí no puede poseer otra determinación sino aquella en la cual las cosas se hallan o se encuentran, el receptáculo vacío de otras cosas menos elementales. Visto desde aquí, el territorio es también algo abstracto, separado, en sí y, en cierto modo, autorreferente.

Pero sabemos que esta cadena de reducciones llegó a su final sin que lo real se encontrara allí como un dato. Al contrario, a poco de decepcionar este proyecto reduccionista moderno, se fue haciendo claro que lo que se llamó las cosas entendidas como datos se presentaban, más bien, como sistemas dinámicos; como tramas o entramados, como redes, y que en estas condiciones de interconexiones múltiples, ningún ámbito podía ser dominante, ni lógica ni ontológicamente, sino que tales interrelaciones se daban como interdependencias, correlaciones, coexistencias o inter-retroacciones complejas. En cada momento, una cosa era, entonces, lo que era con relación a otra, en una trama que tampoco resultaba definitiva, cerrada o aislada, ya que obedecía siempre a dinámicas constituidas e instituidas por su propio movimiento. De aquí que en el proceso de instauración y desarrollo de relaciones, de imaginarios, de identidades territoriales, etc., se hable, más bien, en orden a evidenciar procesos de construcción o creación de territorios o de espacios. Así, el territorio remite obligadamente a ese proyecto/trayecto de apropiación que lo va ordenando según sus tramas de complejidades —económicas, sociales, políticas, culturales, etc.- - y sus constantes reenvíos de unos a otros y de ellas con sus sujetos territoriales. De aquí que, cada vez, el territorio se presente como un tejido de coherencias, pero también de incoherencias, de cercanías y lejanías; de armonías y desarmonías, de encuentros y desencuentros, de presencias y ausencias, de nostalgias y hastíos, de recuerdos y olvidos. Conciencia y memoria son parte significativa de esos tramados/entramados como también lo son las razones y emociones, la sensibilidad y la acción, la palabra y el silencio, etc. Pues bien, a esta nota de precisas influencias mutuas, podemos denominar la condición de reciprocidad del territorio.

Íntimamente ligada a esta condición de reciprocidad encontramos la nota que parece complementaria y co-implicada con ella. Para ubicarnos con mayor propiedad, retrotraigámonos a la situación moderna, según la cual, en el contexto del idealismo, la reducción muestra claramente que a cada nivel de la cadena de 
procesos le corresponde un grado de autonomía, alcanzando la realidad más elemental esta doble condición: a mayor autonomía, mayor realidad. Por esto, el afán moderno por descubrir las leyes generales que rigen los distintos órdenes, y a éstos entre sí, es en esa cualidad donde se aloja su ser por sí, su ser absoluto, la verdad. Probar, entonces, el grado de verdad que algo ostenta es equivalente a probar su mayor o menor libertad de ser o de sentido, lo que debía coincidir con la simplicidad de los datos elementales, sólo encubiertos por esa aparente confusión, producto de una complejidad también aparente. Poner en duda esa aparente simplicidad como signo de verdad conlleva, entonces, poner en duda y sospechar de la verdad de la autonomía. Desde ese momento, la sospecha abre el camino a la consideración de que las interdependencias impedían también las autonomías, fuesen éstas del tipo que fueran (lógicas, físicas, ontológicas, políticas, éticas o estéticas). Entonces, nada fue ya absoluto y definitivo, sino un ir dándose, constituyéndose, unos con relación a otros, unos respecto de otros. De modo que, contra toda apariencia, no hay sujetos territoriales autónomos e independientes de los territorios, ni éstos son sin aquéllos. Por tanto, no hay sujetos des-territorializados como no hay territorios sin sujetos territoriales. Fenómenos privilegiados que prueban este reenvío constante de unas cosas a otras, las hallamos hoy día en múltiples asuntos histórico-sociales, tales como el viaje (Augé, 2002), el ir de un lugar a otro, tanto en las crecientes migraciones como en el turismo pero, también, en las luchas desatadas en el rescate de territorios, efectivos o ficticios, que van poblando los múltiples imaginarios de nuestra época, ya nada moderna. Sin duda, podemos llamar a esta nota la condición de inherencia del territorio. Según ella, al territorio le es inherente serlo para quienes lo piensan y sienten, lo conciben y vivencian como parte de sí mismos, sin lo cual no lo serían, como tampoco lo sería el territorio, ya que la idea de territorio vacío, la nada de territorio como algo indeterminado, su remisión al vacío, es un absurdo.

Pero no podemos concluir sin referirnos a la que, acaso, sea la característica más notable, la nota que sin duda atrae la atención actual como una revelación que puede atribuirse nuestro tiempo. Llamamos a esta nota la condición imaginaria del territorio y señalamos a continuación algunos hitos importantes de esta ideapercepción. Según ella, el concepto de territorio refiere la construcción de un proyecto-trayecto que no está dado sin más, sino que es construido, creado imaginativamente como un a priori que una comunidad tenderá a materializar, según las circunstancias histórico-sociales en que se crea o inventa el proyecto y su itinerario ideal, es decir, según y cómo lo dibuje su emoción y su utopía. En este sentido, el territorio es parte de un sueño colectivo en el que han de concretarse sus fines y valores porque cree en ellos. No se trata, entonces, de una opinión o de un sistema racional de ideas, sino de una idea-creencia en el sentido que Ortega entendía por convicción (1962); una fe, por lo tanto, algo que está más 
cerca de la sensibilidad que de la razón como la concebía la Modernidad. Hay en ella mucho de emoción, de sentimiento vivo, de deseo; un afán casi irracional por superar un estado de cosas insatisfactorias y una búsqueda no menos emocional de identidad. Entonces, el territorio está en el corazón y en la geografía poética antes que en la geografía efectiva de un sitio o de un pedazo de tierra y, por esto, resulta inconmensurable con las medidas exactas de la geometría; sólo se le puede medir con la metáfora del horizonte que se desplaza con el movimiento de la mirada; más allá de la mirada misma. Pero ese más allá no es, propiamente, un afuera sino un dentro: el territorio es — según esto— algo que se lleva al tiempo que se es llevado por él. El territorio se produce como se produce lo poético: creándolo. Y como la utopía es una de las expresiones de lo imaginario, el territorio, también lo es. Sin embargo, esto es solamente una parte: la otra, "contradictoria" con ella, es la defensa, también irracional, de ese sueño colectivo, el elemento ideológico que sirve de marco justificatorio de la utopía. El territorio es, desde aquí, aquel espacio apropiado y no transable ni intercambiable por otros sueños. Tradiciones, mitologías, creencias, son funciones inequívocas que dan forma a ese imaginario y, al mismo tiempo, sus expresiones más sólidas. Cuando el turista compara otros territorios con el propio, o cuando el migrante lleva su territorio encarnado en materialidades que tienen para él un valor simbólico inequívoco, lo que hacen es situarse en lo propio, descubrirse en lo ajeno como aquello que les remite a sí mismo, inalienable y eterno. Por esto, el territorio es aquello Otro en el que uno ha de hallarse como Mismo y entenderse desde ahí.

\section{TERRITORIO Y METAFÍSICA}

Queremos, finalmente, fundamentar en forma breve y sólo como una tesis, esta relación en un apunte que persigue situarnos, también, en la tendencia más reciente y que afirma la no independencia de la epistemología respecto de la metafísica; la imposibilidad de que aquella sea considerada como disciplina autónoma. Y de todas las "razones" que cabe traer y tener en cuenta, hay una que nos conforma por su carácter de principio. Se trata de que los conceptos son un tipo de realidades que refieren, remiten o hacen alusión a otras realidades que resultan apuntadas en ellos, realidades efectivas, conceptuales o virtuales e imaginarias, por cuya realidad cabe, también interrogar y que deviene inseparable del concepto, si bien, perfectamente distinguible. Por esto, al discutir sobre esas realidades — en este caso la realidad del territorio - no se trata de una discusión sobre palabras o términos o conceptos, sino de aquello a lo que éstos hacen referencia, a lo que de verdad es el territorio en su condición más esencial y que puede ser dicho de distintos modos. El concepto, en las perspectivas más actuales, ha de referir y decir lo que el territorio es realmente; por eso las notas apuntadas lo son tanto de la realidad como del concepto. Desentrañar estas complejidades es, hoy por hoy, una tarea permanente de una teoría del territorio. Por esto, 
nociones como espacialidad y territorialidad están siempre como a horcajadas entre la metafísica y la epistemología, del mismo modo que otras notas que se sitúan, al parecer, en la misma tensión epistémico-metafísica y que, por eso, no las hemos referido aquí, son las del territorio en tanto patrimonio y en tanto testimonio, realidades éstas que tienen en la actualidad un gran valor sociohistórico para la comprensión de identidades e imaginarios sociales. Epistemológicamente, forman parte también de esa trama de conceptos que Morin, Ortega o McLuhan gustan llamar galaxias, concepto según el cual las teorías son redes en las que ningún concepto está aislado o es autosuficiente. Con otras palabras, que hemos de entender que en esa galaxia debe ser posible visualizar y entender el carácter dialógico de los conceptos entre sí y con sus entornos, textuales y no textuales, visualizar y entender su condición de realidades determinadas por su recursividad en la que ellos son tanto productos como productores de significación $\mathrm{y}$, también, que en uno cualquiera de ellos ha de poder comprenderse su relación con los demás, porque de algún modo contiene a los demás, es decir, es hologramáticamente los demás.

\author{
Universidad de los Lagos* \\ Departamento Humanidades y Arte \\ Avda. Alcalde Fuchslocher 1305, Osorno (Chile) \\ nvergara@ulagos.cl
}

\title{
BIBLIOGRAFÍA
}

Augé, Marc. Los no lugares. Espacios del anonimato. Barcelona: Gedisa, 2002.

Bachelard, Gastón. La poética del espacio. México: F.C.E., 1996.

------ La filosofía del no. Buenos Aires: Amorrortu, 1992.

Boisier, Sergio. Modernidad y Territorio. Santiago: Cuadernos del Ilpes, 1996.

Castoriadis, Cornelius. La institución imaginaria de la sociedad. Buenos Aires: Tusquets Ensayo, 2007.

Figuras de lo pensable. México: F.C.E., 2002.

Feal, Norberto. "La ficcionalización del territorio", en Bifurcaciones 4, 2005. www.bifurcaciones.cl

Foucault, Michel "Espacios diferentes", en Filosofia, Estética y Hermenéutica. Obras esenciales III. Barcelona: Paidós Ibérica, 1999.

Giménez, Gilberto. "Territorio, paisaje y apego socio-territorial", en Regiones culturales, culturas regionales. México: Consejo Nacional para la Cultura y las Artes, 2004.

Gómez, César; Ma Gisela Hadad (sf). "Territorio e Identidad. Reflexiones sobre la construcción de territorialidad en los movimientos sociales latinoamericanos". (En línea).

Heidegger, Martín. "La época de la imagen del mundo", en Sendas perdidas. Buenos Aires: Losada, 1960. 
Kuhn, Thomas S. La estructura de las revoluciones científicas. Santiago: F. C. E., 1993. Maffesoli, Michel. "La espacialización del tiempo", en Ciudades 61. Puebla: RNIU, 2004. Martín-Barbero, Jesús. "Pensar juntos espacios y territorios", en www.mediaciones.net Morin, Edgar. Introducción al pensamiento complejo. Barcelona: Gedisa, 2006.

------ Ciencia con consciencia. Barcelona: Anthropos, 1982.

Ortega y Gasset, José. Origen y epílogo de la filosofía. Madrid: Revista de Occidente, Col. El Arquero, 1966.

------ Historia como sistema. Madrid: Revista de Occidente, Col. El Arquero, 1962.

Ortíz, Renato. "Otro territorio", en Antropología 12, 1996.

Popper, Karl. Conocimiento objetivo. Madrid: Tecnos, 1992.

Ricoeur, Paul. Freud: una interpretación de la cultura. México: Siglo XXI, 2002.

Santos, Milton. Por otra globalización. Del pensamiento único a la conciencia universal. Bogotá: Convenio Andrés Bello, 2004.

----- Metamorfosis del espacio habitado. Barcelona: Oikos-Tau, 1996.

Sartre, Jean Paul. ¿Qué es la literatura?. Buenos Aires: Losada, 1967.

------ El hombre y las cosas. Buenos Aires: Losada, 1965.

Silva, Armando (sf). "El territorio: una noción urbana", en www.fastio.com 